\title{
A Lipid-Based Oral Supplement Protects Skin Cells in Culture from Ultraviolet Light and Activates Antioxidant and Anti-Inflammatory Mechanisms
}

\author{
Steven R. Hall(D, $\mathrm{PHD}^{1,6}$, Anna-Jean Reid, $\mathrm{MSc}^{6}$, Jasmine Eng ${ }^{1}$, Brendan T. McKeown, $\mathrm{MSc}^{2,5}$, \\ Marc St-Onge, $\mathrm{BSC}^{6}$, Kerry B. Goralski ${ }^{1}$, $\mathrm{PHD}^{1-5^{*}}$ \\ ${ }^{1}$ College of Pharmacy, Faculty of Health, Dalhousie University, Halifax, Nova Scotia, Canada B3H 4R2 \\ 2Department of Pharmacology, Faculty of Medicine, Dalhousie University, Halifax, Nova Scotia, Canada B3H 4R2 \\ ${ }^{3}$ Department of Pediatrics, Faculty of Medicine, Dalhousie University, Halifax, Nova Scotia, Canada B3H 4R2 \\ ${ }^{4}$ Division of Hematology/Oncology, IWK Health Centre, Halifax, Nova Scotia, Canada B3K 6R8 \\ ${ }^{5}$ Beatrice Hunter Cancer Research Institute, Halifax, Nova Scotia, Canada B3H 4R2 \\ ${ }^{6}$ Bend Beauty, Inc., Halifax, Nova Scotia, Canada B3J 0C7 \\ *0 Corresponding Author: kerry.goralski@dal.ca
}

\begin{abstract}
Overexposure to ultraviolet (UV) light is associated with multiple health risks, from sunburn and prematurely aging skin to the development of skin cancers. The ingestion of photoprotective natural compounds through diet or supplementation is one method to increase the skin's UV-resistance. This study's primary objective was to determine the cellular photoprotective properties of an ingestible skincare supplement (trade name "Anti-Aging Formula" [AAF]) and compare them to its constituent active ingredients: fish oil-derived omega-3s eicosapentaenoic acid (EPA) and docosahexaenoic acid (DHA), borage-derived omega-6 gamma-linolenic acid (GLA), paprika- and marigold-derived carotenoids, zeaxanthin and lutein, respectively, and vitamin D3. AAF, but not the separate individual ingredients, significantly increased the viability of primary human dermal fibroblasts after UVA exposure compared to the vehicle control. AAF and EPA/DHA-containing fish oil demonstrated similar UVB photoprotective properties whereas GLA, the carotenoids, and vitamin D3 had no significant effect. The second objective was to explore possible mechanisms of action of AAF's photoprotective effects. AAF-treatment increased cellular antioxidant activity and the expression of genes in the glutathione and peroxiredoxin (PRDX)/thioredoxin (TXN) antioxidant pathways, suggesting an antioxidant mechanism of action. It also diminished cellular arachidonic acid (AA) levels and decreased the expression of the downstream pro-inflammatory prostaglandin-endoperoxide synthase 2 (PTGS2) gene, suggesting an anti-inflammatory mechanism of action. In conclusion, AAF is UVA/B photoprotective when applied directly to primary human dermal fibroblasts. In addition, its photoprotective effects are mainly due to its EPA/DHA components and may relate to its cellular antioxidant effects and inhibition of the AA/PTGS2 inflammatory pathway.
\end{abstract}

KEYWORDS: Antioxidants; borage oil; cell culture; dietary lipids; fish oil; inflammation; lutein; omega-3 and -6 fatty acids; photoprotection; zeaxanthin

\section{Introduction}

The cells that make up our skin protect us from our environments' stressors, such as pathogens, pollution, and UV light. Overexposure to UV radiation causes a number of premature aging effects, including skin wrinkling, loss of elasticity, or age spots, and is considered a "complete carcinogen" due to its ability to initiate and promote the growth of cancerous tumours by damaging 


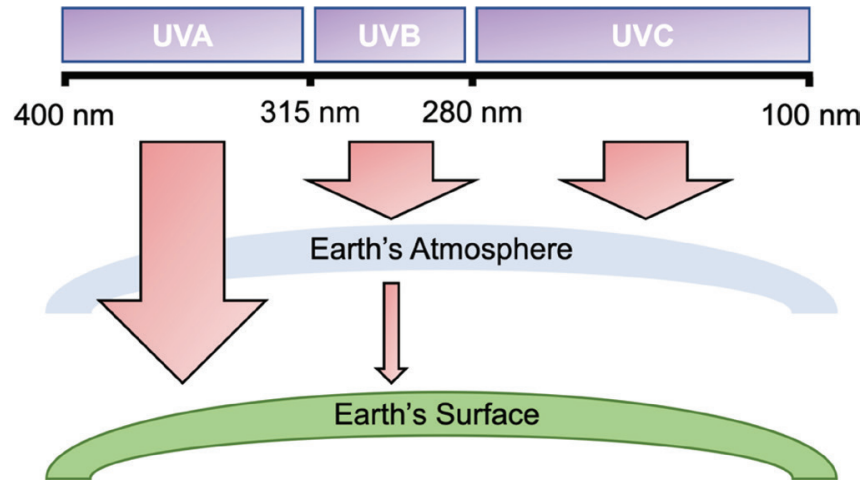

Figure 1. Types of UV radiation. The spectrum of UV radiation is divided into UVA $(315-400 \mathrm{~nm})$ and UVB (280-315 nm), which reach the earth's surface, and UVC (100-280 nm), which is blocked by the earth's atmosphere. Figure adapted from D'Orazio, et al. [1].

and mutating skin cell DNA [1-4]. Fibroblasts, found in the dermis layer, are considered the key drivers of the ageing process as they are quiescent, reside in the skin for years, and accumulate macromolecular damage over time [5-7].

The UV radiation that reaches the Earth's surface (and our skin) is comprised of predominantly UVA (90$95 \%)$ with a lesser amount of UVB (5-10\%), both of which can induce photoaging and photocarcinogenesis (Figure 1) [1,3]. The damaging effects of UVB occur predominantly in the epidermal skin layer [1] and result from direct damage and lesions to DNA [8] while the mutagenic and carcinogenic effects of UVA, which penetrates deeply into the dermal layer [1], primarily result from the generation of reactive oxygen species (ROS) [9] which react with and damage DNA, proteins, and lipids [10].

While the best way to reduce the damaging effects of UV light is to avoid excessive exposure by staying indoors, using sunscreen, or wearing sun-protective clothing [11], an additional method is through dietary consumption or supplementation of compounds called photoprotectors that systemically increase the skin's resistance to UV radiation. Certain photoprotectant molecules can enhance DNA repair, reduce UV-induced immunosuppression, ROS activity, and even the incidence of skin cancers [12].

AAF contains a mixture of the omega- 3 long chain polyunsaturated fatty acids (LCPUFAs) EPA and DHA, the omega-6 LCPUFA GLA, and the carotenoids lutein and zeaxanthin, which individually display anti-inflammatory or anti-oxidant properties [13-16]. Ingestion of EPA and DHA has also been shown to clinically reduce sunburn, skin photosensitivity, photoageing, and photocarcinogenesis $[13,17]$ and the ingestion of the carotenoids lutein and zeaxanthin clinically reduce ocular
[18] and dermal phototoxicity [16, 19]. In a clinical trial, daily ingestion of the commercial skincare supplement AAF was photoprotective based on an average $39 \%$ and $84 \%$ increase in minimal erythema dose (MED; the smallest amount of UV radiation that produces skin redness) after 4 and 8 weeks, respectively. Additionally, $100 \%$ of the trial's 28 participants had higher MED values after 8-weeks of supplementation versus their baseline values [20].

In an effort to better understand the photoprotective activity of AAF at the cellular level, we aimed to: develop methodology to quantify UVA/B photoprotection using human dermal fibroblasts, compare the photoprotective effects of AAF versus its individual components, and develop insight into AAF's cellular photoprotective mechanisms of action.

\section{Materials \& Methods}

\section{Materials}

AAF was obtained from Anti-Aging Formula capsules (Bend Beauty, Inc., Halifax, NS, Canada). AAF contains $0.91 \mathrm{M}$ EPA and 0.28 M DHA derived from fish oil (FO), $0.11 \mathrm{M}$ GLA from borage seed oil (BSO), $2.3 \mathrm{mM}$ lutein from marigold flower extract (MFE; Tagetes erecta), $1.2 \mathrm{mM}$ zeaxanthin from paprika extract (PE; Capsicum annuum), and $17 \mu \mathrm{M}$ vitamin (Vit) D3, with the remaining non-medicinal components being beeswax, olive oil, sunflower lecithin, natural mint flavouring, safflower oil, tocopherols, ascorbyl palmitate, and medium chain triglycerides, encapsulated in bovine gelatin capsules. Molecular biology grade water, fibroblast medium (Medium 106), low serum growth supplement (LSGS), fetal bovine serum (FBS), penicillin and streptomycin, $\mathrm{H}_{2} \mathrm{O}_{2}$, 5-(and 6-)chloromethyl-2'7'-dichlorodihydrofluorescein diacetate (CM-DCFH - -DA), trypsin/EDTA, trypsin neutralizer, Alexa Fluor 488 Phalloidin, Super Script II Reverse Transcriptase, and a handheld e-series $\mathrm{UVA}_{365} / \mathrm{UVB}_{312}$ lamp were purchased from Thermo Fisher Scientific (Burlington, Ontario, Canada). A radiometer with UVA/B sensors was purchased from Solar Light Company (Glenside, Pennsylvania, USA). SsoAdvanced Universal SYBR Green Supermix and Aurum Total RNA Mini Kit was purchased from BioRad (Mississauga, Ontario, Canada). Dako Fluorescent Mounting Medium was purchased from Agilent (Santa Clara, California, USA). All other chemicals were purchased from Sigma Aldrich (Oakville, Ontario, Canada).

\section{Cells}

Primary human dermal fibroblasts (C0135C; Cascade Biologics) were cultured in Medium 106 supplemented with LSGS and $100 \mathrm{IU} / \mathrm{mL}$ penicillin, $250 \mu \mathrm{g} / \mathrm{mL}$ 
streptomycin (complete fibroblast medium). Cells were split weekly and medium changed twice a week. Cells were maintained in a humidified, $95 \%$ air $/ 5 \% \mathrm{CO}_{2}$ atmosphere at $37^{\circ} \mathrm{C}$ (standard conditions) for a maximum of three weeks (six passages), after which they began to senesce.

\section{Dissolution of AAF}

Carotenoids, such as lutein and zeaxanthin, are known to be difficult to use in cell culture studies due to their poor solubility in aqueous solutions [21]. With percentages (v/v) relative to the total solution volume, $10 \%$ AAF (or $10 \% \mathrm{ddH}_{2} \mathrm{O}$ for vehicle control) was dissolved in $10 \%$ tetrahydrofuran (THF) [22] supplemented with $0.00125 \%$ butylated hydroxytoluene (BHT) [23], 75\% dimethyl sulfoxide (DMSO), and 5\% FBS [23-25].

\section{AAF Fibroblast Dose Determination}

Thiazolyl blue methyltetrazolium bromide (MTT) cell viability assays were completed in AAF-treated fibroblasts (0.0025-0.04\%), as previously described [26] with the minor alteration that the MTT reaction was 4 hours. The maximum tolerated concentration (MTC) is defined as the highest AAF concentration that did not significantly reduce cell viability; $50 \%$ of MTC $\left(\mathrm{MTC}_{1 / 2}\right)$ was then used for all subsequent experiments [27].

\section{Photoprotection Trials}

Fibroblasts were treated with the $\mathrm{MTC}_{1 / 2}$ of $\mathrm{AAF}$ $(0.005 \%)$, equivalent concentrations of individual active ingredients (EPA-/DHA-containing FO, GLAcontaining $\mathrm{BSO}$, lutein-containing MFE, zeaxanthin-containing PE, or Vit D3), or vehicle for up to 13 days at standard conditions.

\section{MTT assays}

Zero-, 5-, and 12-day treated cells were seeded (10,000 cells/well, 96-well plate), left to adhere overnight in $0.005 \%$ AAF treatment-, the AAF vehicle, or no-treatment containing medium, re-treated the following day and again left overnight until the target treatment times were reached. The medium was aspirated and replaced with 100-200 mL of treatment-free complete fibroblast medium (UVA assays) or $50 \mu \mathrm{L}$ phosphate buffered saline (PBS; UVB assays). The cells were exposed to UVA (216-324 J/ $\mathrm{cm}^{2}, \sim 12-18$ hours), UVB (31.25-24,000 $\mathrm{mJ} / \mathrm{cm}^{2}, \sim 0.2-30$ minutes), or not exposed (baseline) at standard conditions. The UV-exposed medium was replaced with treatment-containing complete fibroblast medium, and the cells were left to recover overnight. MTT assays were then completed as described above. The percent-cell viability was calculated by normalizing to the baseline values.

\section{Fluorescent microscopy assays}

Thirteen-day AAF-treated fibroblasts seeded on $25 \times 75 \times 1.0 \mathrm{~mm}$ coverslips inside 6-well plates [28] (400,000 cells/well) were left to adhere overnight in $0.005 \%$ AAF treatment- or AAF vehicle-containing medium. The medium was then replaced with $1 \mathrm{~mL}$ treatment-free complete fibroblast medium (UVA assays) or PBS (UVB assays), and plates were exposed to $100 \mathrm{~J} / \mathrm{cm}^{2} \mathrm{UVA}, 1 \mathrm{~J} / \mathrm{cm}^{2} \mathrm{UVB}$, or No UV (baseline). As per published methods, the cells were then treated with $5 \mathrm{mg} / \mathrm{mL}$ of the cell-death indicator propidium iodide (PI), fixed in 4\% Paraformaldehyde, treated with $1 \mathrm{U}$ methanolic Alexa Fluor 488 phalloidin (F-actin stain), and $1 \mu \mathrm{g} / \mathrm{mL}$ Hoechst 33258 (membranepermeable nucleic dye) $[29,30]$. Cell-adhered coverslips were mounted on microscope slides using Dako Fluorescent Mounting Medium and images taken using a Zeiss LSM 710 confocal microscope $\left(\mathrm{Ex}_{405} / \mathrm{Em}_{405-485}\right.$ for Hoechst 33258, $\mathrm{Ex}_{488} / \mathrm{Em}_{495-550}$ for phalloidin, $\mathrm{Ex}_{561} /$ $\mathrm{Em}_{565-620}$ for PI). Percent of dead versus total cells was calculated using Equation 1.

$\%$ of dead versus total cells

$$
=\left(\frac{\# \text { of PI stained nuclei }}{\# \text { of Hoechst 33258-stained nuclei }}\right) \times 100 \%
$$

\section{Antioxidant Trials}

Fibroblasts were treated with AAF or AAF vehicle for up to 14 days and seeded the same way as described in Photoprotection Trials, MTT assays. After the target treatment times were reached the media was aspirated and replaced with complete fibroblast medium containing $\mathrm{H}_{2} \mathrm{O}_{2}(11.1-2,700 \mu \mathrm{M})$ or equivalent $\mathrm{ddH}_{2} \mathrm{O}$ vehicle for 48 hours. MTT assays were completed, and half-maximal inhibitory concentrations ( $\mathrm{IC}_{50}$ values) calculated as measures of $\mathrm{H}_{2} \mathrm{O}_{2}$ cytotoxic potency [26].

To quantify AAF's effects on intracellular ROS activity, fibroblasts were seeded at 10,000 cells/well in black-sided clear-bottomed 96-well plates, left overnight at standard conditions, then treated with $7.5 \mu \mathrm{M}$ $\mathrm{CM}-\mathrm{DCFH}_{2}-\mathrm{DA}$ for $1 \mathrm{~h}$ in complete fibroblast medium. This solution was aspirated, the wells washed with PBS, and the cells treated with $900 \mathrm{mM} \mathrm{H}_{2} \mathrm{O}_{2}$ or $\mathrm{ddH}_{2} \mathrm{O}$ vehicle in complete fibroblast media for 1 hour, after which fluorescence was read $\left(\mathrm{Ex}_{485}, \mathrm{Em}_{528}\right)$ as a measure of intracellular ROS activity [31]. To determine if there was a direct chemical interaction between AAF ingredients and $\mathrm{H}_{2} \mathrm{O}_{2}$ the assay was repeated in the absence of fibroblasts where AAF (0.005\%) or AAF vehicle in complete fibroblast medium was mixed with $900 \mathrm{mM} \mathrm{H}_{2} \mathrm{O}_{2}$ or $\mathrm{ddH}_{2} \mathrm{O}$ and $3.75 \mu \mathrm{M} \mathrm{CM}-\mathrm{DCFH}_{2}-\mathrm{DA}$ for 1 hour. The fold-increases in ROS activity were calculated as follows: 


$$
\text { Fold increase }=\frac{F_{\text {avg,treatment }}}{F_{\text {avg,vehicle }}}
$$

Where $F_{\text {avg.treatment }}$ is the average fluorescence in the $\mathrm{H}_{2} \mathrm{O}_{2}$-treated wells and $F_{\text {avg,vehicle }}$ is that of the $\mathrm{ddH}_{2} \mathrm{O}$ treated wells [31].

\section{Cellular Lipid Profile Analysis}

Fibroblasts grown for 14 days in $0.005 \%$ AAF or vehicle were stored in $12 \mathrm{~mL} \mathrm{2:1} \mathrm{chloroform:methanol} \mathrm{with} 0.01$ mg internal standard tricosanoic acid (23:0). Cells were lysed by sonication and lipids extracted using a modified Folch method [32]. Extracted lipids were converted to methyl esters using $0.5 \mathrm{~N} \mathrm{H}_{2} \mathrm{SO}_{4}$ in methanol $\left(100^{\circ} \mathrm{C}\right.$, 1 hour) [33]. Fatty acid analysis was performed on recovered samples $(0.10 \mathrm{mg} / \mathrm{mL})$ using splitless injection $\left(250{ }^{\circ} \mathrm{C}\right.$ injector temperature) on a gas chromatograph (Bruker) with DB-23 column (Agilent Technologies) and flame ionization detector (GCFID). Temperature program used: initial temperature $\left(60^{\circ} \mathrm{C}, 0.5\right.$ minutes), increased to $150^{\circ} \mathrm{C}$ at $45^{\circ} \mathrm{C} / \mathrm{min}$, temperature held for 2 minutes, then increased $\left(5.1^{\circ} \mathrm{C} / \mathrm{min}\right)$ to a final temperature of $220^{\circ} \mathrm{C}$ and held for 5.77 minutes; 24 -minute total run time. FID was set to $270{ }^{\circ} \mathrm{C}$. Samples analyzed in triplicate. Fatty acid profiles reported as mass percent of total fatty acid identified.

\section{RNA Isolation, Reverse Transcription, and Quantitative Polymerase Chain Reaction (qPCR)}

Quantitative PCR was performed on total RNA isolated from 14-day AAF- $(0.005 \%)$ or vehicle-treated fibroblasts 6 hours after UVA- $\left(100 \mathrm{~J} / \mathrm{cm}^{2}\right)$ or UVB$\left(1.5 \mathrm{~J} / \mathrm{cm}^{2}\right)$ exposure, or baseline-controls, as previously described [29]. Table 1 contains the gene-specific primers used.

\section{Statistical Analysis}

All data are presented as mean \pm standard error of the mean (SEM) of at least three independent trials.
Unpaired t-tests were performed for dual comparisons. One-way or two-way analysis of variances (ANOVAs) were performed for multiple comparisons with one or two independent variables, respectively, and followed by Dunnett's or Tukey's multiple comparisons tests, respectively. A difference was considered significant if $P \leq 0.05$.

\section{Results}

\section{AAF-Treatment Protects Human Dermal Fibroblasts from UVA/B-induced Cell Death}

Treatment with AAF (0.02\%) reduced fibroblast viability to $52 \%$. Therefore, AAF's MTC was $0.01 \%$ and the concentration used in all subsequent trials, the $\mathrm{MTC}_{1 / 2}$, was $0.005 \%$ (Figure 2A). UVA exposure $\left(216 \mathrm{~J} / \mathrm{cm}^{2}\right)$ reduced the viability of the vehicle-treated fibroblasts to $19 \%$, which increased to $55 \%, 80 \%$, and $66 \%$ when the fibroblasts were pre-treated with $0.005 \%$ AAF for 1-, 7-, or 14-days, respectively (Figure $2 \mathrm{~B}$ ). UVB's $\mathrm{IC}_{50}$ quantified via MTT cell viability assays was 1.7 -fold higher in 14 -day AAF- versus vehicle-treated fibroblasts (Figure $2 \mathrm{C}$ ) versus vehicle-treated cells, fibroblasts pre-treated with AAF were $31 \%$ and $11 \%$ more viable after UVA or UVB exposures, respectively (Figures 2D-E). None of the individual components significantly increased cell viability after UVA exposure; only FO significantly increased cell viability after UVB exposure, by $10 \%$.

\section{AAF Helps Preserve Fibroblast Morphology Following UVA/B Exposure}

Fibroblasts treated with vehicle or AAF for 14 days had intact, elongated actin fibers and no PI-stained nuclei (Figure 3A, left). In comparison, the vehicle-treated cells exposed to UVA or UVB had a diffuse F-actin staining pattern and lack of elongated actin fibers, reduced fibroblast density and size, and brightly red PI-stained nuclei indicating cell death (Figure 3A, top middle and right). The AAF- and UVA-treated cells demonstrated

Table 1. PCR primers used to determine the expression of relevant genes in primary human dermal fibroblasts.

\begin{tabular}{|c|c|c|}
\hline Gene & PCR forward primers $\left(5^{\prime}-3^{\prime}\right)$ & PCR reverse primers $\left(5^{\prime}-3^{\prime}\right)$ \\
\hline PTGS1 & GCACAGGAGCCTGCACTC & GTCACACTGGTAGCGGTCAA \\
\hline PTGS2 & CTGATGATTGCCCGACTCCC & CGCAGTTTACGCTGTCTAGC \\
\hline GCLC & GGAAGTGGATGTGGACACCAGA & GCTTGTAGTCAGGATGGTTTGCG \\
\hline GSS & GGAGCCTCTTGCAGGATAAAC & GAGACGAGCGGTAAAGTC \\
\hline GSR & GAGATGGCAGGGATCCTGTCAGC & АTTCTGGAATTCGTCTACGATGATATGACC \\
\hline PRDX1 & TTTGGTATCAGACCCGAAGC & TCCCCATGTTTGTCAGTGAA \\
\hline$T X N$ & GGTGAAGCAGATCGAGAGCA & CCACGTGGCTGAGAAGTCAA \\
\hline TXNRD1 & CCACTGGTGAAAGACCACGTT & AGGAGAAAAGATCATCACTGC \\
\hline GAPDH & GAGTCAACGGATTGGTCGT & TTGATTTGGAGGGATCTCG \\
\hline$A C T B$ & GGACTTCGAGCAAGAGATGG & AGCACTGTGTTGGCGTACAG \\
\hline
\end{tabular}




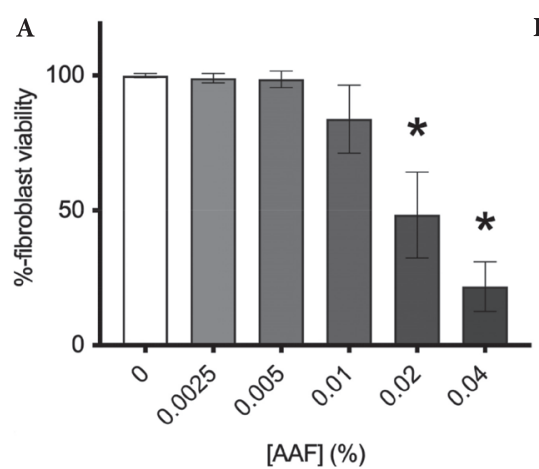

D

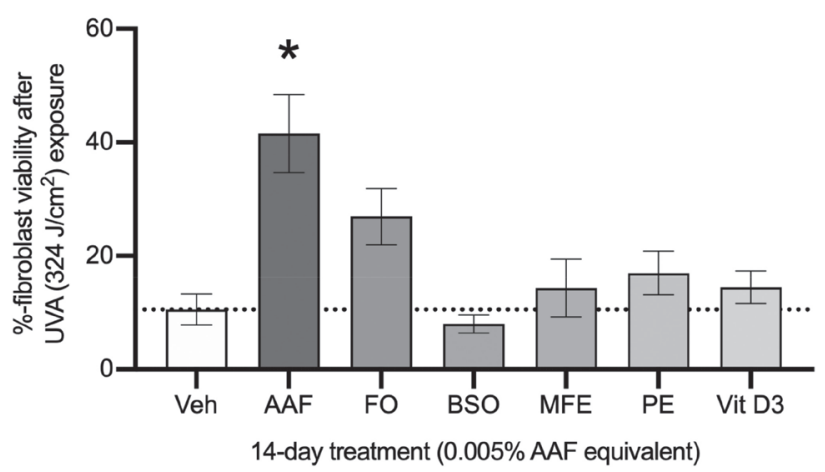

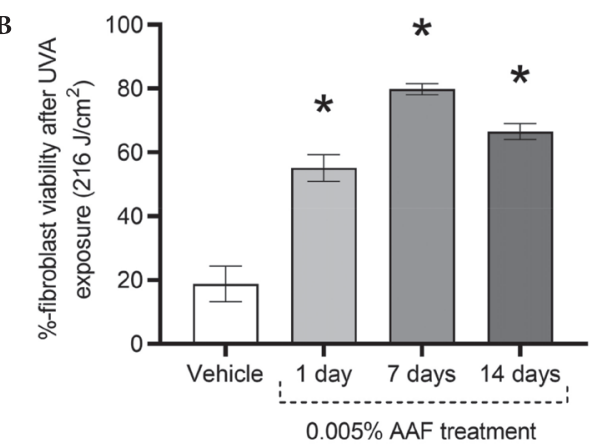

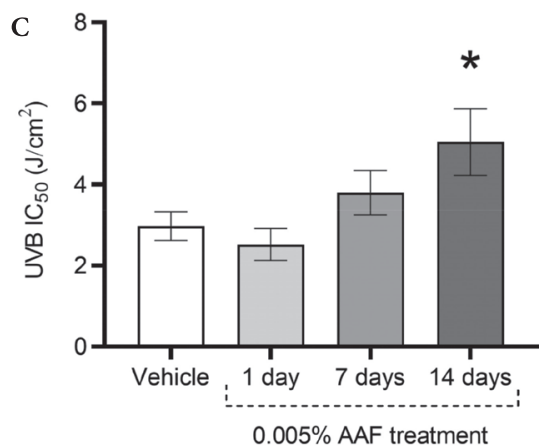

E

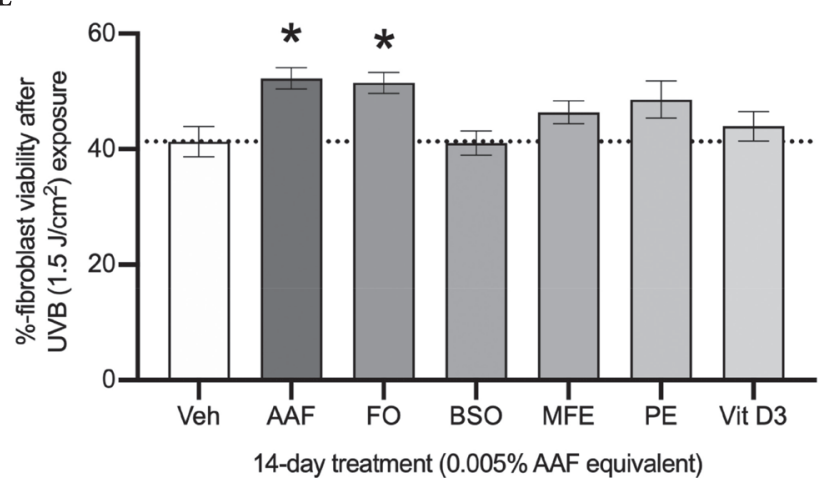

Figure 2. AAF is photoprotective in human primary dermal fibroblasts. (A) Primary human dermal fibroblasts were treated with varying concentrations of AAF to establish the MTC. The fibroblasts were then treated with AAF at the determined MTC $_{1 / 2}(0.005 \%)$ or vehicle for 1-, 7-, or 14-days followed by (B) UVA exposure (216 J/cm²) or (C) UVB exposure (31.25-24,000 m// $\left.\mathrm{cm}^{2}\right)$ followed by MTT cell viability-quantifying assays to evaluate its cellular photoprotective effects. Fibroblasts were treated with the AAF vehicle (Veh), AAF, or the formula's individual active components alone: EPA- and DHA-containing fish oil (FO), GLA-containing borage seed oil (BSO), lutein-containing marigold flower extract (MFE), zeaxanthin-containing paprika extract (PE), or vitamin D3 (Vit D3) for 14-days followed by (D) UVA-exposure $\left(324 \mathrm{~J} / \mathrm{cm}^{2}\right)$ or (E) UVB-exposure $\left(1.5 \mathrm{~J} / \mathrm{cm}^{2}\right)$. *Signifies that the value is significantly different from that of the vehicle-treatment control in that figure, as calculated using one-way ANOVAs followed by Dunnett's multiple comparisons test $(P<0.05)$.

similar morphology to the No UV (baseline) control cells, albeit with a small reduction in cell density, while the AAF- and UVB-treated cells had decreased cell density, more diffuse F-actin staining, and some faint PI-staining (Figure 3A, bottom middle and lower right). Staining with the cell membrane-permeable Hoechst 33258 (blue) provided a total cell count (Figure 3B). Using Equation (1), the percentage of dead versus total fibroblasts was $98 \%$ for vehicle-treated versus $2 \%$ for AAF-treated cells after UVA exposure, and $87 \%$ for vehicle-treated versus $6 \%$ for AAF-treated cells after UVB exposure (Figure 3C).

\section{AAF-treatment Protects Fibroblasts from the ROS, $\mathrm{H}_{2} \mathrm{O}_{2}$}

The $\mathrm{IC}_{50}$ value for $\mathrm{H}_{2} \mathrm{O}_{2}$ increased from $221 \mu \mathrm{M}$ in vehicle-treated fibroblasts to 435,537 , and $558 \mu \mathrm{M}$ after 1-, 7-, and 14-day AAF-treatments (Figure 4A). $\mathrm{H}_{2} \mathrm{O}_{2}$-treatment increased intracellular ROS activity by 8.8 -fold relative to the $\mathrm{H}_{2} \mathrm{O}_{2}$-vehicle $\left(\mathrm{ddH}_{2} \mathrm{O}\right)$ in the AAF vehicle pre-treated cells (Figure $4 \mathrm{~B}$ ). This fold-increase was reduced to 4.5-, 4.4-, and 4.3-fold in the 1-, 7-, and 14-day AAF-treated fibroblasts. $\mathrm{H}_{2} \mathrm{O}_{2}$ directly oxidized the ROS-detecting probe, $\mathrm{CM}-\mathrm{DCFH}_{2}-\mathrm{DA}$, in cell-free fibroblast medium, increasing the fluorescent reading by 55 -fold in both the presence and absence of AAF (Figure 4C).

\section{AAF-treatment Alters the Fibroblasts' Lipid Profile}

Representative GCFID chromatograms (Figures 5A-B) and analysis of triplicate fatty acid mass percent data (Figures 5C-F) show that treating the fibroblasts with AAF for 14-days enriched GLA, EPA, and DHA by 3.1-, 5.8-, and 1.2-fold, and diminished AA by 1.4-fold to $0.7 \times$ of what was quantified in the vehicle-treated cells, without significantly changing total fatty acid content (Figure 5G). 


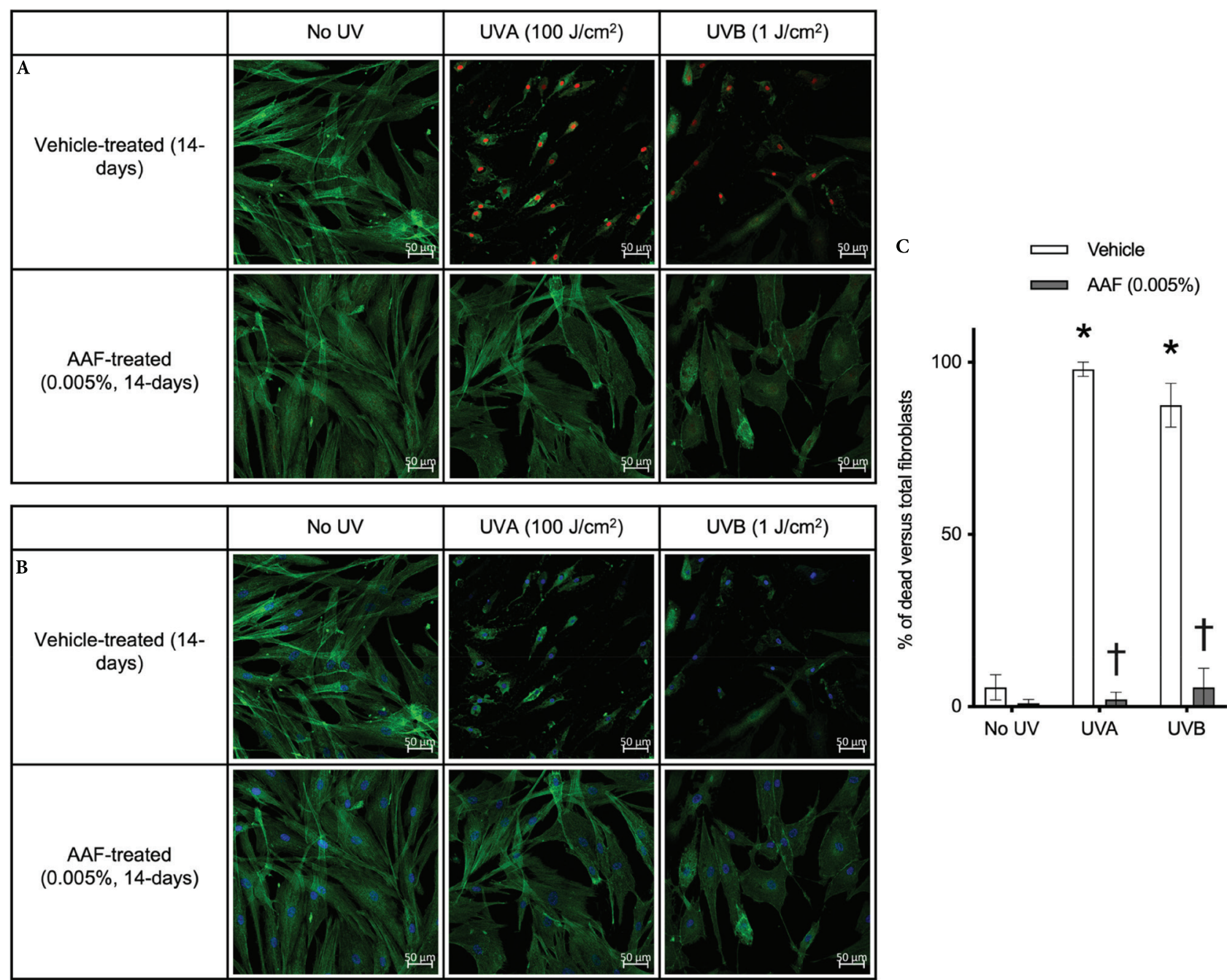

Figure 3. AAF preserves cellular morphology and prevents cell death following UVA and UVB exposure. Human primary dermal fibroblasts were treated with AAF at its $\mathrm{MTC}_{1 / 2}(0.005 \%)$ for 14 days followed by UVA $\left(100 \mathrm{~J} / \mathrm{cm}^{2}\right)$ or UVB (1 J/cm²) exposure. (A) Confocal fluorescent microscopy was used to visualize the effect of AAF treatment and UV-exposure on fibroblast actin cytoskeleton (phalloidin-stained F-actin [green]) and on fibroblast death (PI-stained nuclei [red]). (B) The same fibroblasts were also stained with cell membrane-permeable blue Hoechst 33258 nuclei stain to provide total cell count. (C) The percent of dead versus total cells was quantified using Equation 1. * Signifies the value is significantly higher than the vehicle-treated baseline (No UV) control cells and ${ }^{\dagger}$ signifies value is significantly lower than that of the vehicle-treated cells in the same UV-treatment group, as measured using a two-way ANOVA followed by Tukey's multiple comparisons test $(P<0.05)$.

\section{AAF-treatment Alters the Expression of Genes Involved in Inflammation and Redox Control}

We evaluated three glutathione antioxidant pathway genes, glutamate-cysteine ligase catalytic subunit (GCLC), glutathione synthetase (GSS) and glutathione reductase $(G S R)$, three PRDX/TXN antioxidant pathway genes, peroxiredoxin 1 (PRDX1), thioredoxin $(T X N)$, and thioredoxin reductase (TXNRD1), and two AA/PTGS inflammatory signaling pathway genes, prostaglandin-endoperoxide synthases 1 and 2 (PTGS1/2; also known as cyclooxygenases [COX] 1/2).

Fibroblasts treated with AAF for 14 days had increased GCLC expression versus vehicle-treatment in the No UV baseline control (Figure 6A). UVA treatment increased GCLC expression compared to baseline and the increase was significantly greater in the AAF- versus vehicle-treated cells. GSS and GSR were not significantly affected by AAF treatment alone or by UVA treatment with or without AAF (Figure 6B \& C). In comparison, UVB treatment decreased the expression of all three glutathione antioxidant genes relative to baseline in the vehicle-treated cells. These UVB-mediated decreases in gene expression were not reversed by AAF treatment.

AAF treatment increased the expression of TXNRD1 but not PRDX1 or TXN compared to vehicle treatment in the baseline control cells (Figure 6D, E \& F). 

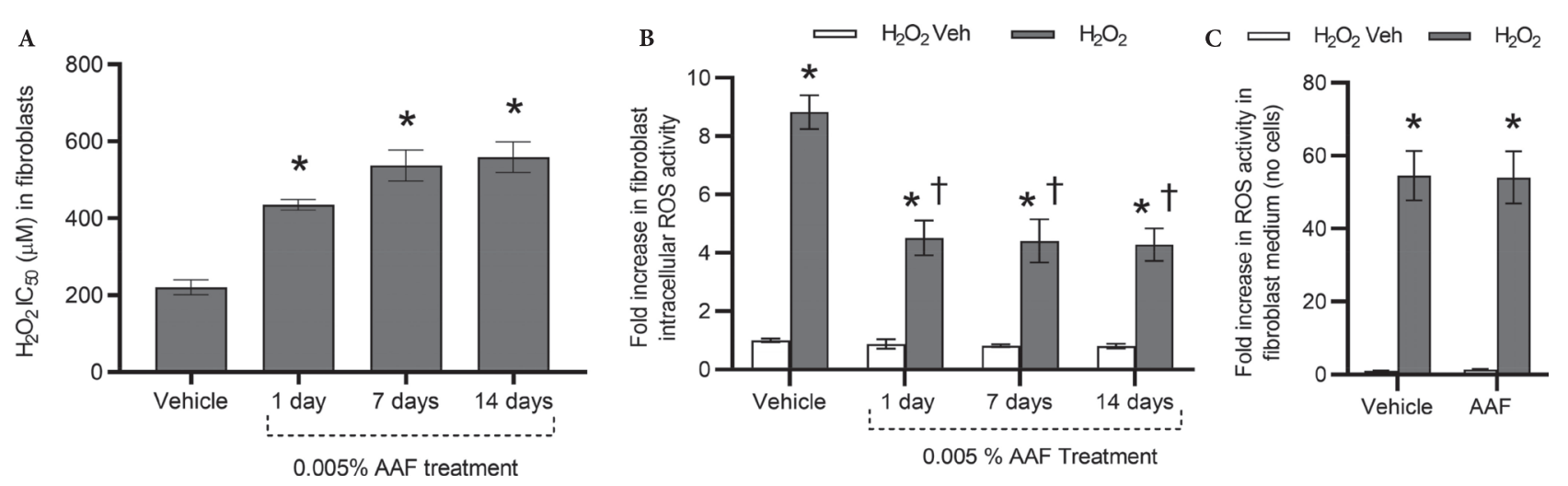

Figure 4. AAF reduces cytotoxicity and intracellular ROS-activity induced by $\mathrm{H}_{2} \mathrm{O}_{2}$. Primary human dermal fibroblasts were treated with AAF (0.005\%) for 1-, 7-, or 14-days or AAF vehicle (Vehicle) for 14-days. This was followed by (A) treatment with various doses of the $\mathrm{H}_{2} \mathrm{O}_{2}$ or $\mathrm{dd}_{2} \mathrm{O}\left(\mathrm{H}_{2} \mathrm{O}_{2}\right.$ Veh) after which MTT assays were performed and $\mathrm{H}_{2} \mathrm{O}_{2}$ 's IC $\mathrm{C}_{50}$ values determined, or (B) treatment with the ROS-detecting fluorescent probe, CM-DCFH 2 -DA (7.5 mM, $1 \mathrm{~h}$ ), after which cells were rinsed with PBS and then exposed to a single dose of $\mathrm{H}_{2} \mathrm{O}_{2}$ (900 mM, $1 \mathrm{~h}$ ). Fluorescence was read $\left(\mathrm{Ex}_{485^{\prime}} \mathrm{Em}_{528}\right.$ ) as a measure of intracellular ROS activity using Equation 2. (C) In complete fibroblast medium with no cells, $\mathrm{H}_{2} \mathrm{O}_{2}(900 \mathrm{mM}, 1 \mathrm{~h})$ or $\mathrm{H}_{2} \mathrm{O}_{2}$ Veh was mixed with $3.75 \mu \mathrm{M}$ CM-DCFH 2 -DA and $0.005 \%$ AAF or AAF-vehicle (Vehicle), total ROS quantified, and fold-increase calculated via Equation 2. *Signifies the value is significantly different from the vehicle control as measured using one-way ANOVAs followed by Dunnett's multiple comparisons test (A), or the $\mathrm{H}_{2} \mathrm{O}_{2}$-Veh within each treatment group (B \& C) as measured using a two-way ANOVA followed by Tukey's multiple comparisons test. 'Signifies the value is significantly different from the AAF-Vehicle/ $\mathrm{H}_{2} \mathrm{O}_{2}$-treated cells as measured using a two-way ANOVA followed by Tukey's multiple comparisons test. $P<0.05$ for all analyses.

In UVA-exposed cells, with or without AAF treatment, there was a significant increase in PRDX1,TXN, and TXNRD1 expression relative to the respective baseline controls. In UVB-treated cells, with or without AAF treatment, there was a significant increase in PRDX1 and TXN and a significant decrease in TXNRD1 relative to the respective baseline controls.

AAF treatment did not affect PTGS1 or PTGS2 expression in the baseline control cells. UVA-treatment dramatically increased (130-fold) PTGS2 but not PTGS1 expression in the vehicle-treated cells (Figure $6 \mathrm{G} \& \mathrm{H}$ ). The UVA-mediated induction of PTGS2 was reversed by AAF treatment. UVB treatment, with or without AAF, reduced PTGS1 but not PTGS2 expression.

\section{Discussion}

Primary human dermal fibroblasts were chosen for this study because they are an accepted cell model for photoprotection trials [36-38] and a powerful preclinical tool for investigating changes in normal skin physiology [39]. Building on our previous demonstration of skin photoprotection in humans [20] we have now determined that AAF exerts UVA and UVB photoprotective effects when applied directly to primary human dermal fibroblast cells in culture. Since AAF and not the individual ingredients provided significant UVA photoprotection it suggests that the combined effects of the individual photoprotective components (EPA \& DHA, lutein, and zeaxanthin $[13,18,40])$ are required to mediate the full UVA photoprotective effect of AAF. For both UVA and UVB photoprotection, EPA/DHA containing FO appears to be AAF's primary photoprotective ingredient within this cell culture model.

In the fluorescent microscopy experiments, the lack of PI-stained nuclei in the AAF-treated/UVAexposed cells provide additional evidence of AAF's UVA-photoprotective effects; however, as these cells appeared less dense than the baseline control cells, it did not appear to completely prevent photodamage at the $100 \mathrm{~J} / \mathrm{cm}^{2}$ UVA dose used, which is consistent with the results of the MTT assays. AAF-treated/UVBexposed cells also displayed less PI-staining than the vehicle-treated/UVB-exposed cells, further supporting that AAF was also UVB photoprotective; however, since the AAF-treated/UVB-exposed fibroblasts appeared more rounded and less fibrous than those exposed to UVA, this suggests that the UVB-exposure was more photodamaging. Together, these data provide additional morphological evidence that AAF increased fibroblast photoresistance against both UVA and UVB.

The primary mechanism through which UVA induces cellular toxicity is through the generation of ROS $[3,9]$; alternatively, UVB is cytotoxic primarily by directly damaging cellular DNA [2], though it too can generate ROS as a secondary mechanism of action [41]. 

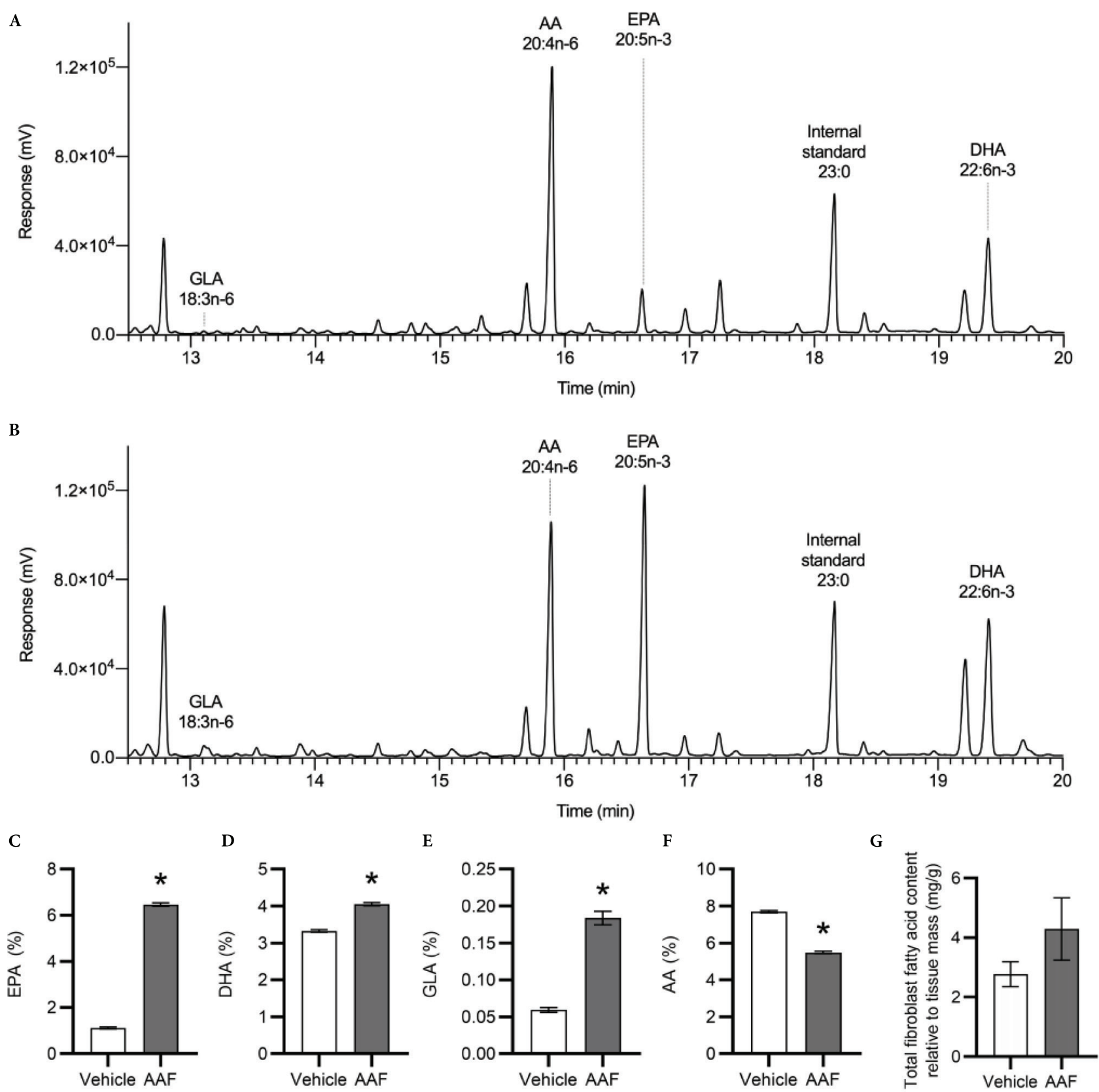

Figure 5. AAF alters lipid profile of the dermal fibroblasts. The fatty acid profile chromatograph examples depict how 14-day vehicle-treated dermal fibroblasts (A) have smaller response (mV) peaks for EPA, DHA, and GLA and a larger AA peak versus 14-day AAF-treated cells (B). Relative to total fatty acid content the mass percent of (C) EPA, (D) DHA, (E) GLA, and (F) AA, and (G) total fatty acid content relative to fibroblast mass are compared in 14-day vehicle- versus 14-day AAF-treated human primary dermal fibroblasts. *Signifies value is significantly different from the vehicle control as determined by two-tailed t-tests $(P<0.05)$.

Based on the known antioxidant activity of AAF's carotenoid components, lutein and zeaxanthin $[15,16,42]$, we hypothesized that one of its photoprotective mechanisms of action was through the induction of increased cellular antioxidant activity. However, due to incompatibilities between UV light and the ROS-detecting probe $\mathrm{CM}-\mathrm{DCFH}_{2}$-DA often used in cellular antioxidant studies [43], we instead indirectly tested this hypothesis by determining if AAF-treatment induced a cytoprotective effect against $\mathrm{H}_{2} \mathrm{O}_{2}$, a ROS induced by UV light in skin cells [41]. These experiments showed that AAF significantly reduced $\mathrm{H}_{2} \mathrm{O}_{2}$-induced cytotoxicity and intracellular ROS production with as little as 24 hours of treatment, supporting a rapid onset and cell-mediated antioxidant mechanism of action.

To explore the possibility that AAF was altering the activity of antioxidant pathways within the cells, we evaluated the effect of AAF on the expression of six 
Glutathione antioxidant pathway

A

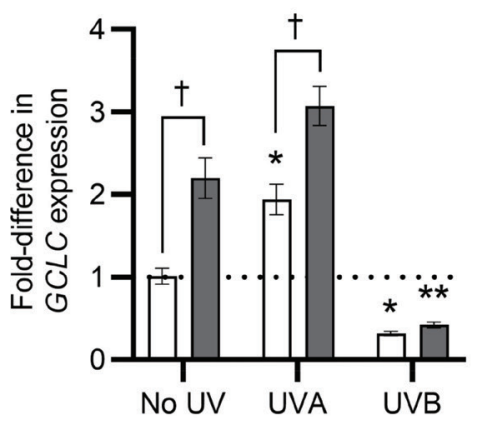

B

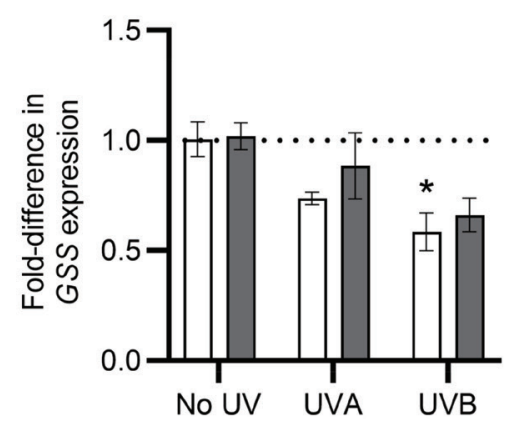

C

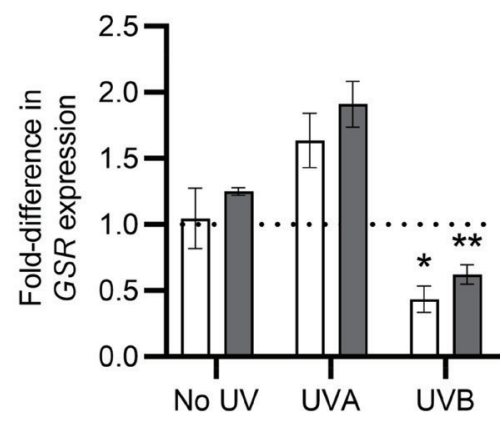

Peroxiredoxin/thioredoxin antioxidant pathway

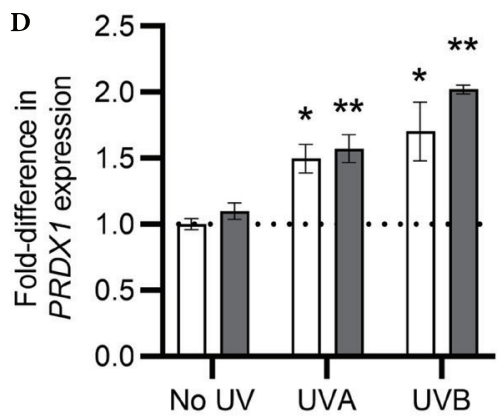

E

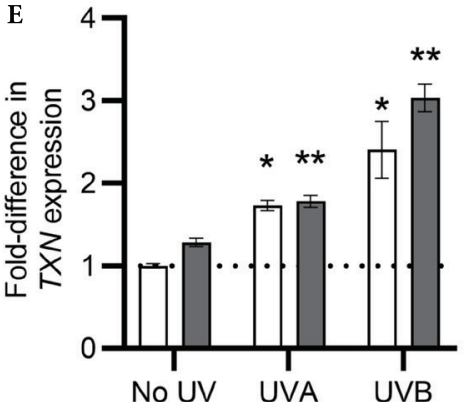

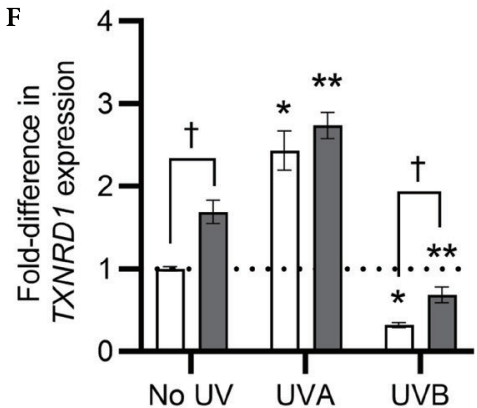

Arachidonic acid/PTGS-inflammatory pathway

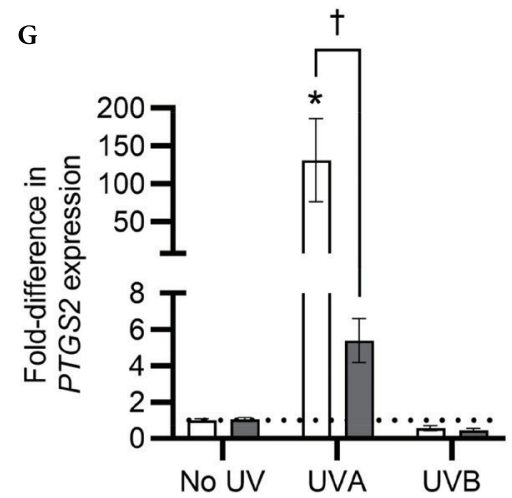

Vehicle

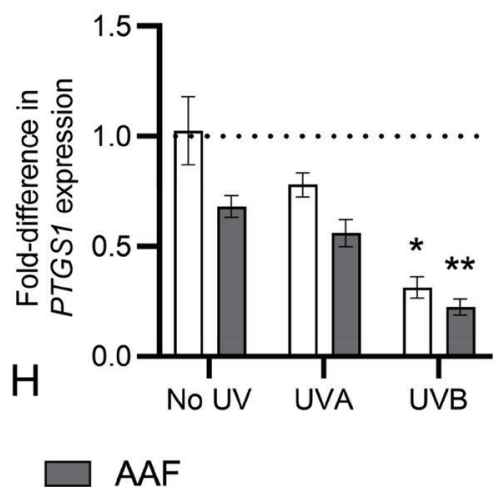

Figure 6. AAF treatment alters the expression of antioxidant and inflammatory pathway genes. The expression of genes involved in the glutathione antioxidant pathway, (A) GCLC, (B) GSS, and (C) GSR, the PRDXITXN antioxidant pathway, (D) PRDX1, (E) TXN, and (F) TXNRD1, and the AAVPTGS-inflammatory pathway, (G) PTGS2 and (H) PTGS1, were quantified using qPCR on cDNA reverse transcribed from the isolated RNA of human primary dermal fibroblasts that had been treated with vehicle or AAF for 14 days, exposed to UVA $\left(100 \mathrm{~J} / \mathrm{cm}^{2}\right)$ or UVB $\left(1.5 \mathrm{~J} / \mathrm{cm}^{2}\right)$, and compared to baseline (No UV). *Signifies value is significantly different from the vehicle-treated/baseline control, ** signifies value is significantly different from the AAF-treated/baseline control, and 'signifies the two values indicated are significantly different from each other, as measured using two-way ANOVAs followed by Tukey's multiple comparisons test $(P<0.05)$ [34]. Statistical analyses were completed on the $\Delta \triangle C_{t}$ values for each gene calculated via the $2 \Delta \triangle C_{t}$ method [35].

genes involved in the glutathione or PRDX/TXN antioxidant pathways. The antioxidant glutathione is biosynthesized in two steps that require the enzymes GCLC
[44-46] and GSS [47], with the activity of GCLC being the rate-limiting step [46]. A third enzyme, GSR, then reduces oxidized glutathione molecules to reactivate 
their antioxidant capacity [48-50]. Our gene expression analysis suggests that AAF's UVA-protective effects may involve increased cellular antioxidant capacity via increased activity of the glutathione pathway, based on how it increased the expression of the rate-limiting GCLC. In the PRDX/TXN antioxidant pathway, PRDXs reduce $\mathrm{H}_{2} \mathrm{O}_{2}$ to water, TXN reduces the PRDXs, TXNR reduces the TXN, and lastly nicotinamide adenine dinucleotide phosphate (NADPH) reduces the TXNR, thus reactivating the pathway [31, 51-53]. Our data suggest that this second photoprotective antioxidant pathway was upregulated by AAF treatment and, since AAF-treatment increased TXNRD1 expression in UVB-exposed fibroblasts, that this upregulation may be partly responsible for AAF's UVB-photoprotective properties. While our data provide initial support for an antioxidant photoprotective mechanism of AAF there are two key limitations: we did not directly measure intracellular ROS accumulation and its reversal by AAF in UV-treated cells, and we did not determine if the AAF-mediated changes in GCLC and TXNRD1 expression result in equivalent changes to the corresponding enzymes or their activity. Therefore, future experiments will be needed to confirm AAF's effects on these cellular antioxidant pathways in the setting of UVA and UVB exposures.

To further understand how AAF-treatment affected the fibroblasts, we performed a fatty acid analysis [54] which confirmed that EPA, DHA, and GLA, the LCPUFAs from AAF's fish and borage oil components, were all successfully integrating into the fibroblasts. A limitation of these trials is that we did not have the analytical capabilities to quantify the non-lipid components included in AAF: lutein, zeaxanthin, or vitamin D3. A key finding was that AAF diminished the mass percent of AA within the fibroblasts. Pro-inflammatory molecules called prostaglandins are biosynthesized from AA through PTGS enzymes [55], and since a major driver of UV-damage is inflammation [56], we hypothesized that AAF-treatment could dampen the inflammatory response through the AA/PTGS-inflammatory pathway as a second mechanism of photoprotection.

PTGS2 expression is induced during acute inflammatory events such as UV-exposure [57, 58], which catalyzes the first step in the conversion of AA to prostaglandins with prostaglandin E2 (PGE2) being the primary prostaglandin synthesized in the skin $[59,60]$, and is both overexpressed in and critical for the development of skin cancers $[59,61]$. Consistent with the literature [59] we observed a robust increase in PTGS2 expression but no effect on the constitutively-expressed PTGS1 following exposure of fibroblasts to UVA. This
UVA-mediated increase in PTGS2 was largely abrogated by AAF (a 24.3-fold reduction). The reduction in cellular AA and PTGS2 expression suggests that AAF's UVA photoprotective mechanisms of action may also include a dampened acute inflammatory response via this pathway, though a limitation of our study is that we did not quantify PGE2 levels to confirm this. However, our data certainly warrants additional studies to confirm or rule out an anti-inflammatory photoprotective mechanism of AAF both in vitro and in vivo.

\section{Conclusions}

This study shows that primary human dermal fibroblasts treated for 2 weeks with AAF are protected against the cytotoxic effects of UVA/B and ROS and suggest that AAF's photoprotective effects may include increased antioxidant capacity and a dampened inflammatory response. While more research is needed to confirm these putative mechanisms of action through enzyme activity-quantifying and in vivo assays, this study introduces valuable methodology for completing cellular photoprotection assays and is an important first preclinical step in determining how AAF induces its photoprotective effects.

\section{List of Abbreviations}

\author{
AA: arachidonic acid \\ AAF: anti-aging formula \\ BHT: butylated hydroxytoluene \\ BSA: bovine serum albumin \\ BSO: borage seed oil \\ CM-DCFH 2 -DA: 5-(and 6-)chloromethyl-2'7'-dichlorodi- \\ hydrofluorescein diacetate \\ DHA: docosahexaenoic acid \\ DMSO: dimethyl sulfoxide \\ EPA: eicosapentaenoic acid \\ FBS: fetal bovine serum \\ FO: fish oil \\ GC: gas chromatograph \\ GCFID: gas chromatography flame ionization detection \\ GCLC: glutamine-cysteine ligase catalytic subunit \\ GLA: gamma-linolenic acid \\ GSH: glutathione \\ GSR: glutathione reductase \\ GSS: glutathione synthetase \\ GSSG: glutathione disulfide \\ $\mathrm{H}_{2} \mathrm{O}_{2}$ : hydrogen peroxide \\ $\mathrm{IC}_{50}$ : half-maximal inhibitory concentration \\ LCPUFA: Iong chain polyunsaturated fatty acid \\ LSGS: Iow serum growth supplement \\ MED: minimal erythema dose
}


MFE: marigold flower extract

MTC: maximum tolerated concentration

$\mathrm{MTC}_{1 / 2}$ : half of the maximum tolerated concentration

MTT: thiazolyl blue methyltetrazolium bromide

NADPH: nicotinamide adenine dinucleotide phosphate

PBS: phosphate buffered saline

PE: paprika extract

PFA: paraformaldehyde

PGE2: prostaglandin E2

PI: propidium iodide

PRDX: peroxiredoxin

PRDX1: peroxiredoxin 1

PTGS1/2: prostaglandin-endoperoxide synthase 1/2

qPCR: quantitative polymerase chain reaction

ROS: reactive oxygen species

THF: tetrahydrofuran

TXN: thioredoxin

TXNRD1: thioredoxin reductase 1

UV: ultraviolet

Vit D3: vitamin D3

\section{Conflicts of Interest}

$\mathrm{SRH}$ was a recipient of a Mitacs Elevate Postdoctoral Fellowship award that was active from December 4, 2017 to December 3, 2019, and which was administered by KBG. The Award covered the salary for SRH and non-salary related research expenses for the study. Bend Beauty, Inc. contributed $60 \%$ of the total Mitacs award value. SRH then received direct salary support from Bend Beauty, Inc. from December 2019 to January 2020. AJR is an employee of and MSO the founder and president of Bend Beauty, Inc.

\section{Ethics Approval and/or Participant Consent}

Our study did not require any ethics approval or participant consent because it was entirely completed using cell culture and in vitro experiments. No animal or clinical trials were completed for this study.

\section{Authors' Contributions}

$\mathrm{SRH}$ : lead the design and planning of the study, collection, analysis, and interpretation of the data, drafted the manuscript, and gave final approval of the version to be published.

(D) https://orcid.org/0000-0001-5314-4970

AJR: contributed to study design and planning, revised the manuscript critically, and gave final approval of the version to be published.
JE: collected and analyzed data, revised the manuscript critically, and gave final approval of the version to be published.

BTM: contributed to study design, revised the manuscript critically, and gave final approval of the version to be published.

MSO: contributed to study design and planning, revised the manuscript critically, and gave final approval of the version to be published.

KBG: contributed to study design and planning, analysis and interpretation of the data, revised the manuscript critically, and gave final approval of the version to be published.

(D) https://orcid.org/0000-0003-0040-5879

\section{Acknowledgements}

We would like to thank Carrie Greene and Dr. Suzanne Budge at the Marine Lipids lab at Dalhousie University for their help with the quantification and analysis of the cellular fatty acid profiles.

\section{Funding}

This study was made possible by funding provided through a Mitacs Elevate Postdoctoral Fellowship $(\mathrm{SRH})$, the Dalhousie Pharmacy Endowment Fund (SRH \& KBG), and Bend Beauty, Inc (SRH, AJR, MSO). BTM is a trainee in the Cancer Research Training Program of the Beatrice Hunter Cancer Research Institute, with funds provided by the Terry Fox Research Institute. BTM and JE were supported by funds from the Natural Sciences and Engineering Research Council (Create grant number 510963).

\section{References}

[1] D'Orazio J, Jarrett S, Amaro-Ortiz A, Scott T. UV radiation and the skin. Int J Mol Sci. 2013;14(6):12222-48. https:// doi.org/10.3390/ijms140612222

[2] Freeman SE, Hacham H, Gange RW, Maytum DJ, Sutherland JC, Sutherland BM. Wavelength dependence of pyrimidine dimer formation in DNA of human skin irradiated in situ with ultraviolet light. Proc Natl Acad Sci USA. 1989;86(14):56059. https://doi.org/10.1073/pnas.86.14.5605

[3] Masuma R, Kashima S, Kurasaki M, Okuno T. Effects of UV wavelength on cell damages caused by UV irradiation in PC12 cells. J Photochem Photobiol B. 2013;125:202-8. https://doi.org/10.1016/j.jphotobiol.2013.06.003

[4] Government of Canada. Health effects of ultraviolet radiation. https://www.canada.ca/en/health-canada/services/ sun-safety/health-effects-ultraviolet-radiation.html 2019. 
[5] Nakamura M, Haarmann-Stemmann T, Krutmann J, Morita A. Alternative test models for skin ageing research. Exp Dermatol. 2018;27(5):495-500. https:// doi.org/10.1111/exd.13519

[6] Richardson AG, Schadt EE. The role of macromolecular damage in aging and age-related disease. J Gerontol A Biol Sci Med Sci. 2014;69 Suppl 1:S28-32. https://doi. org/10.1093/gerona/glu056

[7] Tigges J, Krutmann J, Fritsche E, Haendeler J, Schaal H, Fischer JW, et al. The hallmarks of fibroblast ageing. Mech Ageing Dev. 2014;138:26-44. https://doi.org/10.1016/j. mad.2014.03.004

[8] Rastogi RP, Richa, Kumar A, Tyagi MB, Sinha RP. Molecular mechanisms of ultraviolet radiation-induced DNA damage and repair. J Nucleic Acids. 2010;2010:592980. https://doi.org/10.4061/2010/592980

[9] de Gruijl FR. Photocarcinogenesis: UVA vs. UVB radiation. Skin Pharmacol Appl Skin Physiol. 2002;15(5):31620. https://doi.org/10.1016/s0076-6879(00)19035-4

[10] Schieber M, Chandel NS. ROS function in redox signaling and oxidative stress. Curr Biol. 2014;24(10):R453-62. https://doi.org/10.1016/j.cub.2014.03.034

[11] Lowe NJ. An overview of ultraviolet radiation, sunscreens, and photo-induced dermatoses. Dermatol Clin. 2006;24(1):9-17. https://doi.org/10.1016/j.det. 2005.08.001

[12] Chen AC, Damian DL, Halliday GM. Oral and systemic photoprotection. Photodermatol Photoimmunol Photomed. 2014;30(2-3):102-11. https://doi.org/ 10.1111/phpp.12100

[13] Pilkington SM, Watson RE, Nicolaou A, Rhodes LE. Omega-3 polyunsaturated fatty acids: photoprotective macronutrients. Exp Dermatol. 2011;20(7):537-43. https://doi.org/10.1111/j.1600-0625.2011.01294.x

[14] Kapoor R, Huang YS. Gamma linolenic acid: an antiinflammatory omega-6 fatty acid. Curr Pharm Biotechnol. 2006;7(6):531-4. https://doi.org/10.2174/ 138920106779116874

[15] Morganti P, Bruno C, Guarneri F, Cardillo A, Del Ciotto P, Valenzano F. Role of topical and nutritional supplement to modify the oxidative stress. Int J Cosmet Sci. 2002;24(6):331-9. https://doi. org/10.1046/j.1467-2494.2002.00159.x

[16] Palombo P, Fabrizi G, Ruocco V, Ruocco E, Fluhr $J$, Roberts R, et al. Beneficial long-term effects of combined oral/topical antioxidant treatment with the carotenoids lutein and zeaxanthin on human skin: a double-blind, placebo-controlled study. Skin Pharmacol Physiol. 2007;20(4):199-210. https://doi.org/10.1159/000101807

[17] Asker AF, Jackson D. Photoprotective Effect of Dimethylsulfoxide for Fd-and-C Red No-3 Solutions. Drug Dev Ind Pharm. 1986;12(3):385-96. https://doi. org/10.3109/03639048609026620
[18] Roberts JE, Dennison J. The Photobiology of Lutein and Zeaxanthin in the Eye.J Ophthalmol. 2015;2015:687173. https://doi.org/10.1155/2015/687173

[19] Juturu V, Bowman JP, Deshpande J. Overall skin tone and skin-lightening-improving effects with oral supplementation of lutein and zeaxanthin isomers: a double-blind, placebo-controlled clinical trial. Clin Cosmet Investig Dermatol. 2016;9:325-32. https://doi. org/10.2147/CCID.S115519

[20] Morse NL, Reid AJ, St-Onge M. An open-label clinical trial assessing the efficacyand safety of Bend SkincareAnti-Aging Formula on minimal erythema dose in skin. Photodermatol Photoimmunol Photomed. 2018;34(2):152-61. https://doi. org/10.1111/phpp.12350

[21] Sowmya PR, Arathi BP, Vijay K, Baskaran V, Lakshminarayana R. Role of different vehicles in carotenoids delivery and their influence on cell viability, cell cycle progression, and induction of apoptosis in HeLa cells. Mol Cell Biochem. 2015;406(1-2):245-53. https:// doi.org/10.1007/s11010-015-2442-y

[22] Craft NE, Soares JH. Relative solubility, stability, and absorptivity of lutein and beta-carotene in organicSolvents. J Agr Food Chem. 1992;40(3):431-4. https:// doi.org/10.1021/jf00015a013

[23] Lin CY, Huang CS, Hu ML. The use of fetal bovine serum as delivery vehicle to improve the uptake and stability of lycopene in cell culture studies. BrJ Nutr. 2007;98(1):22632. https://doi.org/10.1017/S0007114507691752

[24] Boesch-Saadatmandi C, Rimbach G, Jungblut A, Frank J. Comparison of tetrahydrofuran, fetal calf serum, and Tween 40 for the delivery of astaxanthin and canthaxanthin to HepG2 cells. Cytotechnology. 2011;63(1):89-97. https://doi.org/10.1007/s10616-010-9324-7

[25] Storey A, McArdle F, Friedmann PS, Jackson MJ, Rhodes LE. Eicosapentaenoic acid and docosahexaenoic acid reduce UVB- and TNF-alpha-induced IL-8 secretion in keratinocytes and UVB-induced IL-8 in fibroblasts. J Invest Dermatol. 2005;124(1):248-55. https://doi. org/10.1111/j.0022-202X.2004.23543.x

[26] Issa ME, Hall SR, Dupuis SN, Graham CL, Jakeman DL, Goralski KB. Jadomycins are cytotoxic to ABCB1-, ABCC1-, and ABCG2-overexpressing MCF7 breast cancer cells. Anticancer Drugs. 2014;25(3):255-69. https:// doi.org/10.1097/CAD.0000000000000043

[27] Corkery DP, Dellaire G, Berman JN. Leukaemia xenotransplantation in zebrafish-chemotherapy response assay in vivo. Br J Haematol. 2011;153(6):786-9. https:// doi.org/10.1111/j.1365-2141.2011.08661.x

[28] Andrade-Vieira R, Goguen D, Bentley HA, Bowen CV, Marignani PA. Pre-clinical study of drug combinations that reduce breast cancer burden due to aberrant mTOR and metabolism promoted by LKB1 loss. Oncotarget. 2014;5(24):12738-52. https://doi.org/10.18632/ oncotarget.2818 
[29] Hall SR, Toulany J, Bennett LG, Martinez-Farina CF, Robertson AW, Jakeman DL, et al. Jadomycins inhibit Type II topoisomerases and promote DNA damage and apoptosis in multidrug-resistant triple-negative breast cancer cells. J Pharmacol Exp Ther. 2017;363(2):196210. https://doi.org/10.1124/jpet.117.241125

[30] Brana C, Benham C, Sundstrom L. A method for characterising cell death in vitro by combining propidium iodide staining with immunohistochemistry. Brain Res Brain Res Protoc. 2002;10(2):109-14. https://doi.org/10.1016/ s1385-299x(02)00201-5

[31] Hall SR, Blundon HL, Ladda MA, Robertson AW, MartinezFarina $C F$, Jakeman $\mathrm{DL}$, et al. Jadomycin breast cancer cytotoxicity is mediated by a copper-dependent, reactive oxygen species-inducing mechanism. Pharmacol Res Perspect. 2015;3(2):e00110. https://doi.org/10.1002/ prp2.110

[32] Budge SM, Cooper MH, Iverson SJ. Demonstration of the deposition and modification of dietary fatty acids in pinniped blubber using radiolabelled precursors. Physiol Biochem Zool. 2004;77(4):682-7. https://doi. org/10.1086/420945

[33] Hilditch TP, Williams PN. The chemical constitution of natural fats. London, UK: Chapman \& Hall; 1964.

[34] Goni R, García P, Foissac S. The qPCR data statistical analysis. Integromics White Paper. 2009:1-9.

[35] Livak KJ, Schmittgen TD. Analysis of relative gene expression data using real-time quantitative PCR and the 2(-Delta Delta C(T)) Method. Methods. 2001;25(4):402-8. https://doi.org/10.1006/meth.2001.1262

[36] Fernandez-Garcia E. Photoprotection of human dermal fibroblasts against ultraviolet light by antioxidant combinations present in tomato. Food Funct. 2014;5(2):28590. https://doi.org/10.1039/c3fo60471c

[37] Hahn HJ, Kim KB, Bae S, Choi BG, An S, Ahn KJ, et al. Pretreatment of ferulic acid protects human dermal fibroblasts against ultraviolet A irradiation. Ann Dermatol. 2016;28(6):740-8. https://doi.org/10.5021/ ad.2016.28.6.740

[38] Huang CH, Li HJ, Wu NL, Hsiao CY, Lin CN, Chang HH, et al. Photoprotective effects of cycloheterophyllin against UVA-induced damage and oxidative stress in human dermal fibroblasts. PLoS One. 2016;11(9):e0161767. https://doi.org/10.1371/journal.pone.0161767

[39] Kisiel MA, Klar AS. Isolation and culture of human dermal fibroblasts. Methods Mol Biol. 2019;1993:71-8. https:// doi.org/10.1007/978-1-4939-9473-1_6

[40] González S, Astner S, An W, Goukassian D, Pathak MA. Dietary lutein/zeaxanthin decreases ultraviolet B-induced epidermal hyperproliferation and acute inflammation in hairless mice. J Invest Dermatol. 2003;121(2):399-405. https://doi.org/10.1046/j.15231747.2003.12355.x
[41] Heck DE, Vetrano AM, Mariano TM, Laskin JD. UVB light stimulates production of reactive oxygen species: unexpected role for catalase. I Biol Chem. 2003;278(25):22432-6. https://doi.org/10.1074/jbc C300048200

[42] Fernandez-Garcia E. Skin protection against UV light by dietary antioxidants. Food Funct. 2014;5(9):1994-2003. https://doi.org/10.1039/c4fo00280f

[43] Burow S, Valet G. Flow-cytometric characterization of stimulation, free radical formation, peroxidase activity and phagocytosis of human granulocytes with 2,7-dichlorofluorescein (DCF). Eur J Cell Biol. 1987;43(1):128-33.

[44] Lu SC. Glutathione synthesis. Biochim Biophys Acta. 2013;1830(5):3143-53. https://doi.org/10.1016/j. bbagen.2012.09.008

[45] Seelig GF, Simondsen RP, Meister A. Reversible dissociation of gamma-glutamylcysteine synthetase into two subunits. J Biol Chem. 1984;259(15):9345-7.

[46] White CC, Viernes H, Krejsa CM, Botta D, Kavanagh TJ. Fluorescence-based microtiter plate assay for glutamate-cysteine ligase activity. Anal Biochem. 2003;318(2):175-80. https://doi.org/10.1016/s00032697(03)00143-x

[47] Njalsson R, Norgren S. Physiological and pathological aspects of GSH metabolism. Acta Paediatr. 2005;94(2): 132-7. https://doi.org/10.1080/08035250410025285.

[48] Deponte M. Glutathione catalysis and the reaction mechanisms of glutathione-dependent enzymes. Biochim Biophys Acta. 2013;1830(5):3217-66. https:// doi.org/10.1016/j.bbagen.2012.09.018

[49] Mannervik B. The enzymes of glutathione metabolism: an overview. Biochem Soc Trans. 1987;15(4):717-8. https://doi.org/10.1042/bst0150717

[50] Meister A. Glutathione metabolism and its selective modification. J Biol Chem. 1988;263(33):17205-8. https://doi.org/10.1126/science.6836290

[51] Arner ES, Holmgren A. The thioredoxin system in cancer. Semin Cancer Biol. 2006;16(6):420-6. https://doi. org/10.1016/j.semcancer.2006.10.009

[52] Lopert P, Day BJ, Patel M. Thioredoxin reductase deficiency potentiates oxidative stress, mitochondrial dysfunction and cell death in dopaminergic cells. PLoS One. 2012;7(11):e50683. https://doi.org/10.1371/journal. pone.0050683

[53] Yoshioka J, Schreiter ER, Lee RT. Role of thioredoxin in cell growth through interactions with signaling molecules. Antioxid Redox Signal. 2006;8(11-12):2143-51. https://doi.org/10.1089/ars.2006.8.2143

[54] Spector AA, Yorek MA. Membrane lipid composition and cellular function. J Lipid Res. 1985;26(9):1015-35.

[55] Ricciotti E, FitzGerald GA. Prostaglandins and inflammation. Arterioscler Thromb Vasc Biol. 2011;31(5):9861000. https://doi.org/10.1161/ATVBAHA.110.207449 
[56] Clydesdale GJ, Dandie GW, Muller HK. Ultraviolet light induced injury: immunological and inflammatory effects. Immunol Cell Biol. 2001;79(6):547-68. https://doi. org/10.1046/j.1440-1711.2001.01047.x

[57] Hellmann J, Tang Y, Zhang MJ, Hai T, Bhatnagar A, Srivastava $\mathrm{S}$, et al. Atf3 negatively regulates Ptgs $2 /$ Cox2 expression during acute inflammation. Prostaglandins Other Lipid Mediat. 2015;116-117:49-56. https://doi. org/10.1016/j.prostaglandins.2015.01.001

[58] Kang YJ, Mbonye UR, DeLong CJ, Wada M, Smith WL. Regulation of intracellular cyclooxygenase levels by gene transcription and protein degradation. Prog Lipid Res. 2007;46(2):108-25. https://doi.org/10.1016/j. plipres.2007.01.001
[59] Rundhaug JE, Mikulec C, Pavone A, Fischer SM. A role for cyclooxygenase-2 in ultraviolet light-induced skin carcinogenesis. Mol Carcinog. 2007;46(8):692-8. https:// doi.org/10.1002/mc.20329

[60] Greenhough A, Smartt HJ, Moore AE, Roberts HR, Williams AC, Paraskeva C, et al. The COX-2/PGE2 pathway: key roles in the hallmarks of cancer and adaptation to the tumour microenvironment. Carcinogenesis. 2009;30(3):377-86. https://doi.org/10.1093/carcin/bgp014

[61] Fischer SM, Pavone A, Mikulec C, Langenbach R, Rundhaug JE. Cyclooxygenase-2 expression is critical for chronic UV-induced murine skin carcinogenesis. Mol Carcinog. 2007;46(5):363-71. https://doi.org/10.1002/ mc.20284

\section{Article Information}

Managing Editor: Kieran Cooley

Peer Reviewers: Roy Golsteyn, Pierre Haddad

Article Dates: Received Jan 17 20; Accepted May 12 20; Published Jun 2220

\section{Citation}

Please cite this article as follows:

Hall SR, Reid A-J, Eng J, McKeown BT, St-Onge M, Goralski KB. A Lipid-Based Oral Supplement Protects Skin Cells in Culture from Ultraviolet Light and Activates Antioxidant and Anti-Inflammatory Mechanisms. Journal of Natural Health Product Research. 2020 Jun 22: 2(1). https://jnhpresearch.com/index.php/jnhpr/article/view/10

DOI Link: https://doi.org/10.33211/jnhpr.10

\section{Copyright}

(c) Steven R. Hall, Anna-Jean Reid, Jasmine Eng, Brendan T. McKeown, Marc St-Onge, Kerry B. Goralski. (2020). Published first in the Journal of Natural Health Product Research. This is an open access article distributed under the terms of the Creative Commons Attribution License (https://creativecommons.org/licenses/by/4.0/), which permits unrestricted use, distribution, and reproduction in any medium, provided the original work, first published in the Journal of Natural Health Product Research, an NHP Publications journal, is properly cited. The complete bibliographic information, a link to the original publication on https://www.jnhpresearch.com, as well as this copyright and license information must be included.

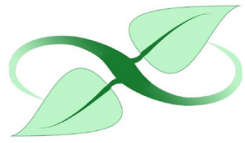

Canadàa

Does the safety, efficacy, and quality of natural health products matter to YOU?

Submit your research article to the Journal of Natural Health Product Research!

Pre-submission inquiries? Send us an email at editorial.office@jnhpresearch.com Facebook, Twitter and LinkedIn: @NHPPublications 